\title{
Effects of Control Parameters on Performance and Emissions of HSDI Diesel Engines: Investigation via Two Zone Modelling
}

\author{
I. Arsie, C. Pianese and M. Sorrentino \\ Dipartimento di Ingegneria Meccanica, Università di Salerno, Via Ponte Don Melillo 1, 84084 Fisciano (SA) - Italy \\ e-mail: iarsie@unisa.it - pianese@unisa.it - msorrentino@unisa.it
}

Résumé - Effets des paramètres de contrôle sur les performances et les émissions de moteurs Diesel HSDI : étude au moyen de modélisation à deux zones - Cet article traite du développement et de la validation expérimentale d'un modèle de combustion à deux zones pour des moteurs Diesel (HSDI) à injection directe à grande vitesse. Ce modèle a pour but d'assister la conception du contrôle du moteur pour les moteurs Diesel common-rail à injections multiples, où le grand nombre de paramètres de contrôle (durée de l'injection, angle de came de l'injection, pression du rail, etc.) rend la réalisation d'expériences extrêmement coûteuse, en termes de temps et d'argent. L'approche de la modélisation est basée sur un modèle de combustion semi-empirique à deux zones, couplé à une analyse d'identification intensive, de manière à mettre en place un outil de prévision permettant de simuler les effets des stratégies de contrôle sur les émissions de combustion et d'échappement. La nébulisation de carburant et la combustion sont simulées en divisant la chambre de combustion en deux volumes de contrôle, représentant le jet de carburant et l'air environnant. Le gicleur de carburant est ensuite divisé en deux zones afin de séparer les phases liquide et vapeur, alors que la zone d'air environnante est composée d'air frais et de gaz résiduels. Les modèles d'évaporation de carburant et de combustion sont basés sur une description semi-empirique proposée par Whitehouse and Way, qui représente la présence de régimes prémélangés et de diffusion. Le modèle de nébulisation du carburant évalue le déplacement du jet dans le cylindre, en utilisant une description empirique du temps de désagrégation et prévoit l'entraînement de l'air au moyen de la conservation du mouvement. Les émissions de NOx et l'échappement de suie sont prévus conformément aux mécanismes, bien connus, proposés respectivement par Zeldovich et Hiroyasu. La précision du modèle a été testée avec succès sur un large ensemble de données expérimentales, composées de presque 100 cycles de moteur mesurés sur un moteur commercial common-rail diesel à multi-injection. En outre, il a suffi de mesurer 9 points de fonctionnement pour identifier le modèle et cela confirme le recours limité aux expériences. Les résultats de la simulation ont aussi démontré que le modèle peut prévoir les effets de différents paramètres d'injection, en cas d'injection simple et multiple, ceci avec une durée courte de simulation. Par conséquent, ce modèle peut être intégré facilement dans un schéma global de simulation pour accomplir des simulations intensives ou des analyses d'optimisation, destinées à minimiser la consommation et/ou les émissions par rapport à une stratégie d'injection (nombre d'injections, durée de l'injection, pression du rail, etc.).

Abstract - Effects of Control Parameters on Performance and Emissions of HSDI Diesel Engines: Investigation via Two Zone Modelling - The paper deals with the development and experimental validation of a two zones combustion model of High Speed Direct Injection (HSDI) Diesel engines. The model is aimed to support the engine control design for common-rail Diesel engines with multiple 


\begin{abstract}
injections, where the large number of control parameters (i.e. injection timing, injection dwell, rail pressure, etc.) makes the recourse to experiments extremely expensive, in terms of time and money. The modelling approach is based on a semi-empirical two-zone combustion model coupled with an intensive identification analysis, in order to implement a predictive tool for simulating the effects of control strategies on combustion and exhaust emissions. Fuel spray and combustion are simulated by dividing the combustion chamber into two control volumes, accounting for fuel jet and surrounding air. The fuel jet is further divided in two zones to separate liquid and vapour phases, while the surrounding air zone is composed of fresh air and residual gases. Fuel evaporation and combustion models are based on the semi-empirical formulation proposed by Whitehouse and Way, which accounts for the occurrence of premixed and diffusive regimes. The fuel spray model evaluates the spray motion into the cylinder, assuming an empirical formulation for the break time, and predicts the air entrainment by means of the conservation of momentum. NOx and soot exhaust emissions are predicted according to the well known mechanisms proposed by Zeldovich and Hiroyasu, respectively. Model accuracy has been successfully tested over a wide set of experimental data, composed of nearly 100 engine cycles measured on a commercial common rail multi-injection Diesel engine. Moreover, only 9 measured operating conditions were needed for model identification, thus confirming the limited recourse to experiments. Simulation results also evidenced that the model can predict the effects of different injection parameters, in case of single and multiple injection, in a short computational time. Therefore its implementation is suitable for the accomplishment of intensive simulations or optimization analyses, aimed to minimize consumption and/or emissions vs. injection strategy (number of injections, injection timing, rail pressure, etc.).
\end{abstract}

\section{INTRODUCTION}

After the introduction of common rail systems, the interest in Diesel engines for automotive application has dramatically grown. A strong increase in fuel economy and a remarkable reduction of emissions and combustion noise have been achieved, thanks to both optimized fuelling strategy and improved fuel injection technology. Namely, the improvement of injector time response, injection pressure and nozzle characteristics have made feasible the operation of multiple injections (up to five or more) and have enhanced the fuel atomization. Altogether these benefits make the combustion cleaner and more efficient, thus reducing both particulate emissions and fuel consumption. Furthermore, the presence of early pilot and pre injection may enable the occurrence of a homogeneous combustion with a reduction of noise and main combustion temperature and with a decrease of NOx emissions.

Despite the technological improvements of fuel injection systems, the methodologies used for Diesel engine control have not yet reached the same maturity as those adopted for SI engine. Nowadays the design of SI engine control is supported by complex computational architectures (i.e. Hardware-In-the-Loop, optimization, virtual reality system, Rapid Prototyping) where the main features are compliant with the opposite requisites of high accuracy and limited computational demand. In the field of electronic control for Diesel engines, it is likely to expect the implementation of methodologies derived from the SI engine in order to gain all the potential benefits of the Common-Rail system. Massive use of advanced mathematical models to simulate powertrain and system components (mechanical and electronic devices) is needed to speed up the design and optimization of engine control strategies. This problem is particularly felt in presence of a large number of control parameters (i.e. injection timing, rail pressure, injection dwell, etc.), as it is the case of multi-jet DI engines, where the exclusive recourse to the experiments would be extremely expensive in terms of money and time.

On the other hand, the complexity of Diesel engine combustion, which is governed by the turbulent fuel-air-mixing, causes an unresolved trade-off between computational time and accuracy. Single zone models based on empirical heat release laws (Barba et al., 2000; Arsie et al., 2004), largely used to simulate SI engine performance and emissions are inadequate to simulate the heterogeneous character of Diesel combustion, especially for pollutants prediction, unless a wide identification analysis is performed. In order to achieve suitable accuracy, most of the studies in the field of Diesel Engine modelling have been addressed to the basic phenomena involved into fuel injection/evaporation, air entrainment, combustion and emission formation (mainly soot). Many advanced models are available in the literature, based on the complete description of multidimensional, turbulent, multiphase flow field inside the cylinder (Patterson et al., 1994; Corcione et al., 1993; Shrivastava et al., 2002; Bella et al., 2002). Despite their accuracy, these models present a large computational demand and are indeed oriented to engine design (combustion chamber shaping, fuel jet / air interaction, swirl) rather than to control design application.

As experienced for the SI engine control design, the implementation of fast and flexible models of reduced order 
is required. The proper solution can be found in a modular approach from single zone toward more physical multi-zone models. These models are coupled with algebraic models (i.e. regressions) identified over a set of experimental data, whose extension is a key factor in the balance between computational effort and accuracy. In order to meet the requirements for engine control design, phenomenological two-zone or multi-zone models have been proposed in literature. Such models are accurate enough to predict fuel evaporation, air entrainment, fuel-air distribution and thermal stratification with a reasonable computational demand (Kouremenos et al., 1997; Arsie et al., 2006). Particularly, the recourse to twozone models, coupled with a detailed identification analysis of the main model parameters, makes it possible to have a predictive tool for simulating, with a reduced computational burden, the effects of control injection variables on combustion process and exhaust emissions formation (Rakopoulos et al., 2003; Arsie et al., 2005).

\section{MODEL STRUCTURE}

The model structure is composed of a main thermodynamic model, which is based on the conservation of energy and volume (Assanis and Heywood, 1986; Hiroyasu and Kadota, 1983; Bi et al., 1999). The model assumes the combustion chamber divided into several zones and simulates the thermodynamic properties in each of them. During the compression stroke, only one homogeneous zone containing the air and the residual gas (air zone, $a$ ) is considered, as shown in Figure 1. When the injection takes place, the fuel jet forms a number of sprays, depending on the number of injection nozzle holes: for each of them a zone of liquid fuel (liquid zone, $l$ ) and a zone containing an homogeneous mixture of fuel and entrained air (mixing zone, $m$ ) are considered. This process is repeated for each injection and results in the formation of two zones $(l$ and $m$ ) for each spray, plus the surrounding zone containing air and residual gas $(a)$. The injected fuel travels into the cylinder at constant speed as a liquid column, until the break-up time elapses. Then it is assumed that the fuel atomizes to fine droplets that travel into the combustion chamber decreasing their velocity and entraining the surrounding air (Hiroyasu and Masataka, 1990; Jung and Assanis, 2001). The spray development of the spray is simulated by a Fuel Spray sub-model, which predicts the spray penetration and velocity and the amount of air entrained into the spray at each time step. The calculations related to the air entrainment are based on momentum conservation. After the break-up time, due to the high surrounding gas temperature, the droplets evaporate and mix with the entrained air.

The Fuel Evaporation sub-model is based on the partial pressure of oxygen and evaluates the overall evaporated mass for each spray at each time step, while neglecting the effect of fuel distribution. Combustion is assumed to start individu-

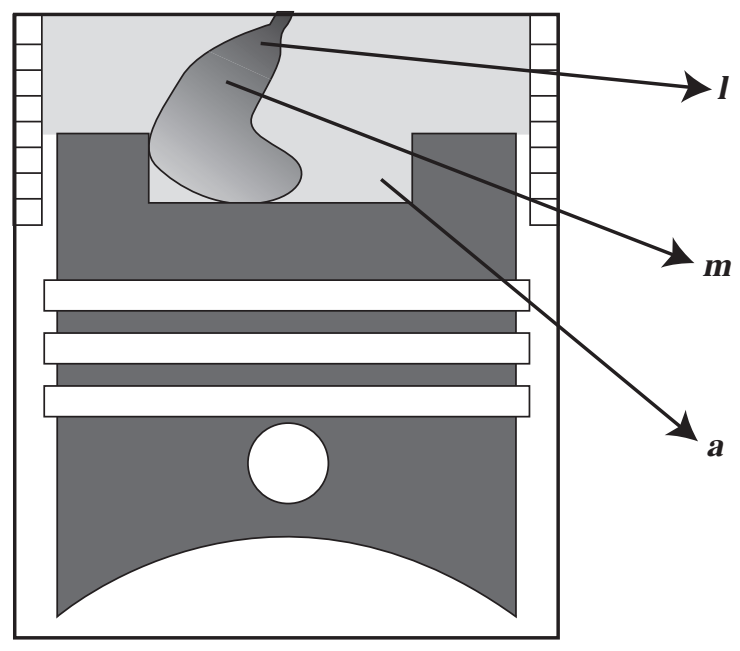

Figure 1

Scheme of air zone $(a)$, liquid fuel zone $(l)$ and mixing zone ( $m$ ) generated at each injection and for each injector spray.

ally in each spray. The burning rate is initially given by an Arrhenius correlation, until it reaches the rate of fuel preparation; then, the burning rate is assumed to be equal to the preparation rate until the end of combustion (Rakopoulos et al., 2003; Ramos 1989).

\subsection{Thermodynamic Model}

The thermodynamic sub-model is based on the energy conservation for an open system applied to each zone (Assanis and Heywood, 1986; Hiroyasu and Kadota, 1983; Bi et al., 1999) and on the volume conservation of the total combustion chamber, as expressed by the two following equations:

$$
\begin{gathered}
\dot{E}_{i}=\dot{Q}_{w, i}-\dot{W}_{i}+\sum_{j, i \neq j} \dot{m}_{i, j} \cdot h_{i, j} \\
\forall i=a, m \quad \forall j=a, l, m \\
V_{c y l}=V_{a}+\sum_{i} \sum_{j} V_{i, j} \\
\forall i=a, l, m \quad \forall j=1 \ldots n_{n h}
\end{gathered}
$$

where $\dot{E}_{i}$ is the rate of change of internal energy in the $i$-th zone, $\dot{Q}_{w, i}$ is the total heat transfer rate to the $i$-th zone, $\dot{W}_{i}$ is the work transfer rate out of the $i$-th zone, $\dot{m}_{i, j}$ is the net mass flow rate leaving the $j$-th zone and entering the $i$-th zone, $h_{i, j}$ is the specific enthalpy of the mass $m_{i, j}, V_{c y l}$ is the instantaneous cylinder volume and $V_{i, j}$ is the instantaneous volume of the $i$-th zone. The subscripts $a, l$ and $m$ refer to air, liquid fuel and mixing zone, respectively, while $n_{n h}$ is the number of the injector nozzle holes. 
The model has been developed by assuming the following hypotheses:

- Uniform pressure into the combustion chamber at each time step.

- Mixture of ideal gas in each zone, with thermodynamic properties depending on temperature, pressure and air-fuel ratio.

- Chemical equilibrium concentration in each zone.

- Only convective heat transfer for the air zone.

- Convective and radiative heat transfer for the spray zones. No heat transfer between the zones.

- Differentiating Equations 1 and 2 with respect to time leads to integrate the rate of change of pressure $(\dot{p})$ and temperature $\left(\dot{T}_{m}\right)$ for the mixing zone of each spray (Arsie et al., 2005).

The thermodynamic gas properties for the mixture of air, fuel and residual gas fraction and for the mixture of burned gases at equilibrium have been computed as function of pressure, temperature and equivalence ratio from the routines proposed by Ferguson (1986).

The convective heat transfer between the air zone and the cylinder wall is estimated by using Woschni's empirical model (Ramos, 1989). The heat transfer rate to the mixing zone is expressed as:

$$
\dot{Q}_{w}=\dot{Q}_{w, r}+\dot{Q}_{w, c}
$$

where $\dot{Q}_{w, r}$ and $\dot{Q}_{w, c}$ are the radiative and convective heat losses from the mixing zone to the wall, evaluated by using the formula of Annand (Ramos, 1989; Heywood 1988) and Woschni's empirical model (Ramos, 1989).

For the mixing zone, the rate of change of the fuel-air equivalence ratio is evaluated as:

$\dot{\phi}=\alpha_{s t}\left(\frac{\dot{m}_{f, b}}{m_{a, e}}-m_{f, b} \frac{\dot{m}_{a, e}}{m_{a, e}^{2}}\right)$

where $\alpha_{s t}$ is the stoichiometric air-fuel ratio, $m_{a, e}$ is the mass of entrained air, computed by the fuel spray model, and $m_{f, b}$ is the mass of burned fuel estimated by the semi-empirical combustion model.

\subsection{Fuel Spray}

The fuel spray submodel describes the fuel motion into the cylinder and the air entrainment. The model does not predict the injection delay $\left(t_{i n j, d}\right)$, which is the time it takes from the ECU injection command and the effective injector opening (Bella et al., 2002), which is considered as a model parameter. After the injection, the fuel motion can be assumed as a liquid column travelling at a constant speed until the breakup time elapses. After the break-up time, the liquid column atomizes to fine droplets entraining the surrounding air and forming the spray. The fuel velocity at the nozzle hole is given by:

$$
U_{b b}=U_{0}=C_{D} \cdot \sqrt{\frac{2 \cdot \Delta p}{\rho_{l}}}
$$

where $\Delta p$ is the pressure drop through the nozzle hole, $\rho_{l}$ is the liquid fuel density and $C_{D}$ is the discharge coefficient of the injector nozzle, whose identification will be discussed in the next session.

The break-up time and the velocity after the break-up are computed by the following empirical equations (Hiroyasu and Masataka, 1990; Jung and Assanis, 2001):

$$
\begin{gathered}
t_{b}=4.351 \frac{\rho_{l} \cdot d_{n}}{C_{D}^{2} \cdot \sqrt{\rho_{a} \cdot \Delta p}} \\
U_{a b}=\frac{2.95}{2} \cdot\left(\frac{\Delta p}{\rho_{a}}\right)^{0.25} \cdot \sqrt{\frac{d_{n}}{t}}
\end{gathered}
$$

where $d_{n}$ is the nozzle hole diameter, $\rho_{a}$ is the air zone density and $t$ is the elapsed time since the start of injection.

The prediction of the entrained air is based on the conservation of momentum, assuming that the sum of the momentum of the mixing and liquid zone is equal to the fuel flow momentum at the nozzle exit:

$$
\int_{0}^{t} \frac{d m_{f, i n j}}{d t} d t \cdot U_{o}=\left(\int_{0}^{t} \frac{d m_{f, i n j}}{d t} d t+m_{a, e}(t)\right) \cdot U_{a b}(t)
$$

where $m_{f, i n j}$ is the mass of injected fuel.

Rearranging and differentiating Equation $8 v s$. time, the air entrainment rate at time $t$ can be obtained as:

$$
\dot{m}_{a, e}(t)=-\frac{\int_{0}^{t} \frac{d m_{f, i n j}}{d t} d t \cdot U_{O}}{\left(U_{a b}(t)\right)^{2}} \cdot \dot{U}_{a b}(t)
$$

The simulation of spray velocity $v s$. crank angle at different rail pressure is shown in Figure 2. The figure evidences that the larger is the rail pressure, the greater is the velocity of the spray; moreover, the higher velocity gradient observable at higher pressure enhances the air entrainment and the fuel-air mixing, with a reduction of combustion time delay.

\subsection{Evaporation and Combustion}

Fuel evaporation and combustion processes are described making use of the semi-empirical model proposed by Whitehouse and Way (see Rakopoulos et al., 2003; Ramos, 1989). According with this modelling approach, the details of fuel atomization and vaporization are neglected and only a fuel preparation rate is considered. The fuel is assumed to be prepared after its atomization, evaporation and micromixing with entrained air. At a fixed time, the prepared fuel depends 


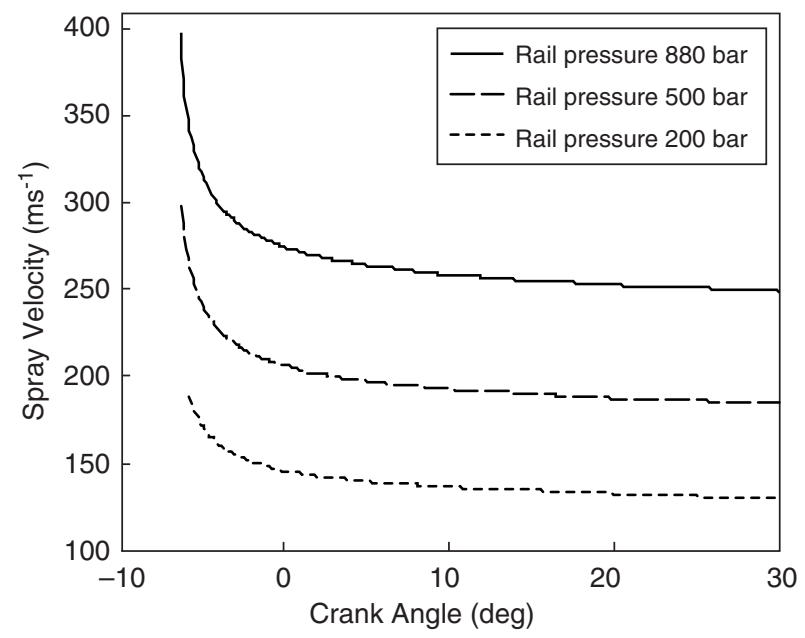

Figure 2

Simulated spray velocity $v s$. crank angle at different rail pressure for the test case 2 .

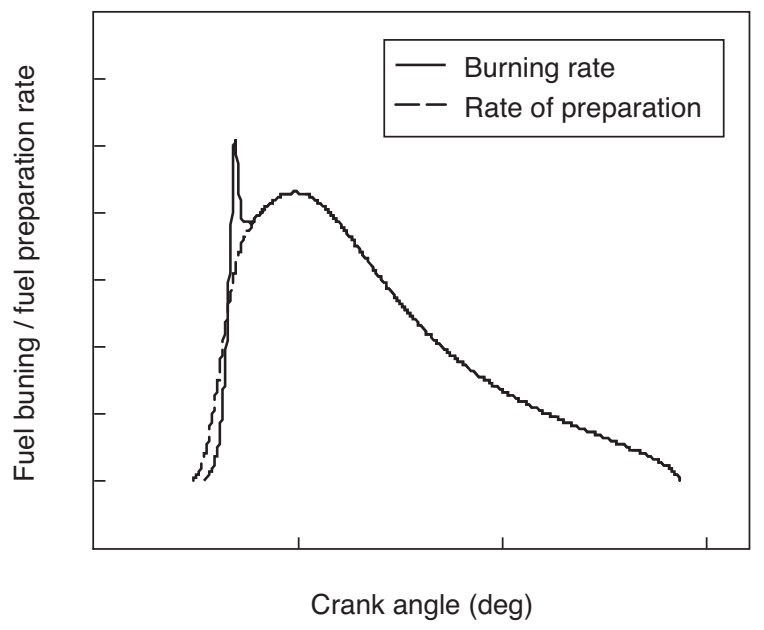

Figure 3

Fuel preparation and fuel burning rate. on the amount of injected fuel until the current time, on the entrained air (through the partial oxygen pressure) and on the amount of fuel which has been injected but not prepared yet, according with the following equation:

$$
\begin{aligned}
\dot{m}_{f, p}(\theta)=C_{1} & \left(\int_{0}^{\theta} \frac{d m_{f, i n j}}{d \theta} d \theta\right)^{1 / 3} \cdot\left(p_{\mathrm{O}_{2}}(\theta)\right)^{0.4} . \\
& \cdot\left(\int_{0}^{\theta} \frac{d m_{f, i n j}}{d \theta} d \theta-\int_{0}^{\theta} \frac{d m_{f, p}}{d \theta} d \theta\right)^{2 / 3}
\end{aligned}
$$

where $\theta$ is the crank angle, $p_{\mathrm{O}_{2}}$ is the oxygen partial pressure and $C_{1}$ is a constant assumed equal to 0.035 (bar $^{-0.4} / \mathrm{deg}$ ) (Rakopoulos et al., 2003).

It is assumed that in the early stages of combustion, the fuel burning rate is controlled by the chemical kinetics and is evaluated as:

$$
\begin{gathered}
\dot{m}_{f, b}(\theta)=\frac{C_{2} \cdot p_{\mathrm{O}_{2}}(\theta)}{N^{\prime} \cdot \sqrt{T_{\text {mean }}(\theta)}} e^{\left(-\frac{T_{A}}{T_{\text {mean }}(\theta)}\right)} . \\
\cdot \int_{0}^{\theta}\left(\frac{d m_{f, p}}{d \theta}-\frac{d m_{f, b}}{d \theta}\right) d \theta \\
T_{\text {mean }}(\theta)=\frac{T_{a}(\theta) \cdot m_{a}(\theta)+\sum_{i=1}^{n_{n h}} T_{m, i}(\theta) \cdot m_{m, i}(\theta)}{m_{a}(\theta)+\sum_{i=1}^{n_{n h}} m_{m, i}(\theta)}
\end{gathered}
$$

where $N^{\prime}\left(\operatorname{rad~s}^{-1}\right)$ is the engine speed. $C_{2}$ and $T_{a}$ are constants here assumed equal to $1.2 \times 10^{10}\left(\mathrm{~K}^{0.5} /(\mathrm{bar} \cdot \mathrm{deg})\right)$ and $16500 \mathrm{~K}$, respectively (Rakopoulos et al., 2003).

According to Equation 12, in the early stages of combustion the preparation rate is greater than the burning rate, with an accumulation of prepared fuel, resulting in a premixed combustion process. As the combustion proceeds, the burning rate dramatically increases until the accumulated prepared fuel is exhausted. From this stage on, preparation and burning rates keep equal until the end of combustion, resulting in a mixing controlled combustion process, as shown in Figure 3.

\subsection{Model Parameters Identification}

A wide identification analysis has been performed in order to evaluate the only model parameter, corresponding to the injector discharge coefficient $C_{D}$ (Equation 6). A further identification analysis has been accomplished to evaluate the injection nozzle delay $t_{i n j, d}$ to the opening command of ECU, which is a characteristic parameter of the injection system. The identification has been carried out by a least square technique via a comparison between predicted and experimental pressure cycles, measured at Élasis laboratories on a commercial FIAT four cylinders, 1.9 liters, Multi-Jet Common Rail Diesel Engine. The identification data set was composed of 9 pressure cycles measured at different engine operations, as it is shown in Table 1. It is worth to note that the identification set is composed of operating conditions with the main 
injection only; therefore a single value of $\mathrm{CD}$ and $t_{i n j, d}$ has been detected for each of the 9 engine operations. The choice of operating points with the main injection only can be explained considering that in case of multiple injections, it is difficult to correlate the effects of each single injection (pilot, pre and main) to the pressure trace; therefore it would be arduous to detect univocally the optimal value of the parameters for every engine operating condition. The table also evidences that the identification set does not include engine operation at low-medium engine speed, which are characterized by having multiple injections.

Moreover, since the aim of the work is to ensure a predictive model in a wide engine operating range (speed and load) and for various injection parameters (nr. of injections, injection timing, rail pressure etc.), the identification analysis was addressed to find out mathematical correlations between the parameters $C_{D}$ and $t_{i n j, d}$ and the engine operating conditions.

TABLE 1

Engine operating conditions for the identification data set

\begin{tabular}{c|c|c|c}
\hline No. & $\begin{array}{c}\text { Engine } \\
\text { Speed (rpm) }\end{array}$ & $\begin{array}{c}\text { Mean effective } \\
\text { pressure (bar) }\end{array}$ & $\begin{array}{c}\text { Number } \\
\text { of injection }\end{array}$ \\
\hline 1 & 4500 & 0.5 & 1 \\
\hline 2 & 4500 & 3 & 1 \\
\hline 3 & 4500 & 5 & 1 \\
\hline 4 & 4500 & 9 & 1 \\
\hline 5 & 4500 & 12 & 1 \\
\hline 6 & 4000 & 11 & 1 \\
\hline 7 & 4000 & 16 & 1 \\
\hline 8 & 3500 & 9 & 1 \\
\hline 9 & 3500 & 12 & \\
\hline
\end{tabular}

As a result of correlation analyses, the best compromise between accuracy and generalization has been obtained using the following relationships for the two parameter $C_{D}$ and $t_{i n j, d}$ expressed as function of volume of injected fuel (qfuel) and engine speed $(\mathrm{N})$ :

$$
\begin{array}{cc}
C_{D}=a_{1}-a_{2} \cdot\left(q_{\text {fuel }} \cdot N\right) & \text { if } q_{\text {fuel }} \cdot N \geq \frac{1-a_{1}}{a_{2}} \\
C_{D}=1 & \text { if } q_{\text {fuel }} \cdot N<\frac{1-a_{1}}{a_{2}} \\
t_{i n j, d}[\mathrm{~ms}]=b_{1}-b_{2} \cdot\left(q_{\text {fuel }} \cdot N\right)
\end{array}
$$

with $a_{1}=1.1774, a_{2}=3.95 \times 10^{-6} \mathrm{~mm}^{-3} \mathrm{rpm}^{-1}, b_{1}=0.64 \mathrm{~ms}$, $b_{2}=1.33 \times 10^{-6} \mathrm{~ms} \mathrm{~mm}^{-3} \mathrm{rpm}^{-1}$. It is worth to note that the proposed relationships can be used to evaluate the parameters $C_{D}$ and for $t_{i n j, d}$ every kind of injection: pilot, pre and main.

\subsection{NO Model}

NOx emissions from Diesel engines are mainly due to the thermal NO formation for dilute (lean mixture and egr) operation, while the contribution from prompt $\mathrm{NO}$ and $\mathrm{NO}_{2}$ can be neglected (Heywood, 1988). The thermal NO formation process is modelled making use of the well known extended Zeldovich mechanism applied to the mixing zone, which considers three reactions with seven species as main responsible for NO production (see Heywood, 1988; Ramos, 1989):

More detailed models have been proposed, as the super extended Zeldovich mechanism by Miller et al. (1998), which accounts for 13 species and up to 67 reactions and can led to a significant improvement of model accuracy. On the other hand this approach could thwart the benefits of phenomenological models because of its higher computational complexity.

According with the well known assumptions on steady state nitrogen formation and equilibrium concentration for the reactants (Heywood, 1988), the Zeldovich mechanism holds the following rate of variation for the $\mathrm{NO}$ concentration (Arsie et al., 1998):

$$
\frac{1}{V_{b}} \frac{d n_{\mathrm{NO}}}{d t}=\frac{2 R_{1}\left\{1-\left(\frac{[\mathrm{NO}]}{[\mathrm{NO}]_{e q}}\right)^{2}\right\}}{1+\left(\frac{[\mathrm{NO}]}{[\mathrm{NO}]_{e q}}\right) \frac{R_{1}}{R_{2+}+R_{3}}}
$$

where $n_{\mathrm{NO}}$ is the number of NO moles in the burned gas volume $V_{b}$, while $R_{1}, R_{2}$ and $R_{3}$ are computed as follows:

$$
\begin{array}{ll}
R_{1}=k_{1}^{+}[\mathrm{O}]_{e}\left[\mathrm{~N}_{2}\right]_{e} & k_{1}^{+}=7.6 \cdot 10^{13} \cdot \exp \left(\frac{-38000}{T}\right) \\
R_{2}=k_{2}^{-}[\mathrm{NO}]_{e}[\mathrm{O}]_{e} & k_{2}^{-}=1.5 \cdot 10^{9} \cdot \exp \left(\frac{-19500}{T}\right) \\
R_{3}=k_{3}^{-}[\mathrm{NO}]_{e}[\mathrm{H}]_{e} & k_{3}^{-}=2 \cdot 10^{14} \cdot \exp \left(\frac{-23650}{T}\right)
\end{array}
$$

The temperature $T$ is in Kelvin, the concentrations are in $\mathrm{mol} / \mathrm{cm}^{3}$ and the subscript $e$ denotes chemical equilibrium.

The indicated reaction rate constants $k_{1}, k_{2}$ and $k_{3}$ are the most frequently used in the literature (Heywood, 1988; Ramos, 1989) and they could present some uncertainty depending on actual temperature and pressure. Several studies have been proposed in order to identify the optimal parameters at different engine operation. Among the others, Miller et al. (1998) proposed a correction factor for the constant $k_{1}$ as function of the instantaneous in-cylinder pressure; at high engine load and pressure, the reaction rate is reduced up to $80 \%$ of the original value, with a significant reduction of the NO prediction. The authors themselves have proposed an identification method based on a decomposition approach for estimating the optimal parameters as function of the engine operating conditions, with 
a significant improvement of model accuracy on a wide set of reference data (Arsie et al., 1998).

\subsection{SOOT Model}

The mechanism of particulate formation is one of the most critical task in Diesel engine modelling. The basic phenomena which characterize the formation, the growth and the oxidation of the soot particles are not completely clear yet. The attempts performed for estimating soot emissions have led to the development of a wide variety of models ranging from phenomenological to empirical (black-box). The more detailed phenomenological models describe the soot formation downstream the fuel jet and in the burned region, estimating the soot mass fraction and the number density of particles; the soot particles are then oxidized in the burned gas region following a surface oxidation mechanism due to oxygen and minor oxidation agents (i.e. radicals) ( $\mathrm{Li}$ and Wallace, 1995).

The most widely adopted modelling approach is the one originally proposed by Hiroyasu, which describes the soot formation and oxidation processes as kinetically controlled by two Arrhenius equations (Hiroyasu and Kadota, 1983). Thus the net soot mass rate is given by the difference between the mass formation rate and the mass oxidation rate:

$$
\frac{d m_{s}}{d t}=\frac{d m_{s f}}{d t}-\frac{d m_{s o}}{d t}
$$

The mass formation rate $m_{s f}$ and the mass oxidation rate $m_{s o}$ are estimated as:

$$
\begin{gathered}
\frac{d m_{s f}}{d t}=A_{f} m_{f v} P^{0.5} \exp \left(-E_{f} / R T\right) \\
\frac{d m_{s o}}{d t}=A_{o} m_{s} Y_{\mathrm{O}_{2}} P^{1.8} \exp \left(-E_{o} / R T\right)
\end{gathered}
$$

where $m_{f v}$ and $m_{s}$ are the mass of fuel vapour and the net mass of soot, respectively, $P$ is the in-cylinder pressure, $Y_{\mathrm{O}_{2}}$ is the oxygen molar fraction, $T$ is the temperature. The preexponential coefficients $A_{f}$ and $A_{o}$ are model parameters to be identified in order to fit the experimental measurements; the activation energies $E_{f}$ and $E_{o}$ are assumed equal to $12500 \mathrm{cal} / \mathrm{mol}$ and $14000 \mathrm{cal} / \mathrm{mol}$, as suggested by Hiroyasu and Kadota (1983).

The model given by Equations 16-18 has been widely implemented in the framework of multi-zone combustion models (Beatrice et al., 1992; Patterson et al., 1994); the soot and oxidation kinetic equations are solved independently for each zone, which is characterized by uniform pressure, temperature and chemical composition. The total soot emissions are then estimated considering the contributions of all the zones. A different approach was proposed by Bayer and Foster (2003), which developed a detailed spray model and solved the soot formation and oxidation (Equations 17, 18) for the whole region bounded by the fuel diffusion flame. This assumption is based on the hypothesis that the soot formation is mainly due to the fuel pyrolysis in the rich core which is characterized by uniform temperature and composition.

\section{RESULTS}

The present section is devoted to analyze the simulation results, achieved for different injection timings and engine operations. This approach allows investigating the generalization features of the model to prove the feasibility of its implementation in computational tools aimed at control strategies design. Furthermore, model accuracy is tested by means of a comparison with a wide experimental data set, which does not include the operating conditions used for the parameters identification.

Figure 4 through Figure 7 show the effects of pre-injection on in-cylinder temperature, fuel burning rate, and pressure for the test cases summarized in Table 2. Figure 4 shows the mixing zone temperature $v s$. crank angle, evidencing that a slight increase of maximum temperature (i.e. $100 \mathrm{~K}$ ) is achieved in case of only main injection (case 2). On the other hand, in presence of pre and main injections (case 1), the maximum temperature is lower along the engine cycle and a thermal stratification occurs among the mixing zones formed by pre and main injections. The reduction of maximum temperature, achieved in test case 1 , is due to the reduced mass of fuel of the main injection, though the total amount of injected fuel is the same in the two cases (see Table 2). This result is confirmed by the burned fuel time history of the main injection, shown in Figure 5 for the two cases, which also evidences that the burned fuel rate is lower when the pre-injection occurs. This behaviour can be explained considering that in case of pre- and main- injections (case 1), when the main injection takes place, in-cylinder pressure and temperature are higher than in case of only main injection (case 1); thus, the ignition time delay is shorter and a reduced amount of prepared fuel is stored before start of combustion. Under these conditions, the premixed combustion, which is characterized by a greater heat release rate, involves only a limited amount of prepared fuel. Figure 6 shows the in-cylinder pressure $v s$. the crank angle, with a very slight increase of pressure peak in case of pre-injection and almost the same IMEP in the two cases. On the other hand, due to temperature reduction (Fig. 4), the occurrence of pre-injection significantly influences the NO formation, as evidenced in Figure 7, where the in-cylinder NO volumes are plotted $v s$. the crank angle; the figure exhibits that lower in-cylinder temperatures result in a dramatic reduction of NO formation rate due to the non linear effect of temperature on kinetic mechanisms. 
TABLE 2

Injection parameters for the test cases 1 and 2

\begin{tabular}{l|c|c|c|c}
\hline & \multicolumn{2}{|c|}{ Main Injection } & \multicolumn{2}{c}{ Pre Injection } \\
\hline & $\begin{array}{c}\text { Injected } \\
\text { Fuel } \\
\left(\mathrm{mm}^{3}\right)\end{array}$ & $\begin{array}{c}\text { Injection } \\
\text { Advance } \\
\left({ }^{\circ} \mathrm{BTDC}\right)\end{array}$ & $\begin{array}{c}\text { Injected } \\
\text { Fuel } \\
\left(\mathrm{mm}^{3}\right)\end{array}$ & $\begin{array}{c}\text { Injection } \\
\text { Advance } \\
\left({ }^{\circ} \mathrm{BTDC}\right)\end{array}$ \\
\hline Case 1 & 14.67 & 7 & 3 & 20 \\
\hline Case 2 & 17.67 & 7 & - & - \\
\hline
\end{tabular}

The model accuracy has been evaluated via comparison between predicted and measured in-cylinder pressure, NO and Soot emissions in a wide engine operating range. The overall test data set was composed of 81 operating conditions measured with engine speed varying from 1000 to $4500 \mathrm{rpm}$, IMEP ranging from 0.5 bar to full load and in correspondence of single (main), double (pre + main) or multi injections (pilot + pre + main). The simulations have been carried out estimating the parameters $C_{D}$ and $t_{i n j, d}$ from the multiple regressions described in Equations 26 and 27.

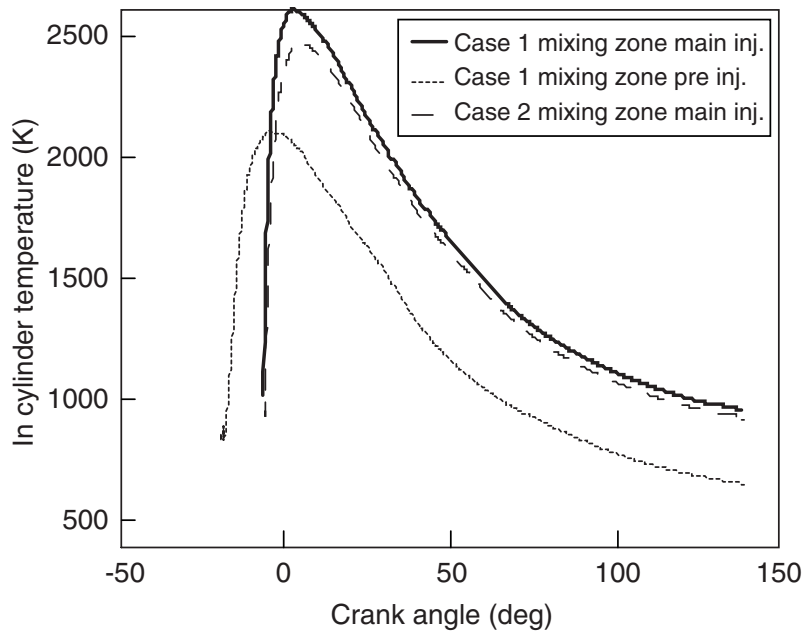

Figure 4

Simulated In-Cylinder Temperatures for test cases 1 and 2.

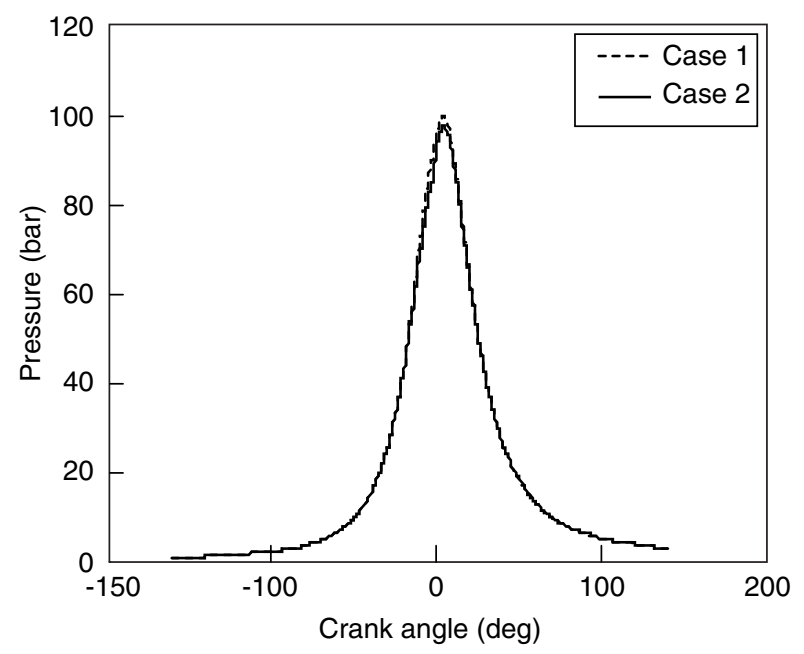

Figure 6

Simulated In-Cylinder Pressure for test cases 1 and 2.

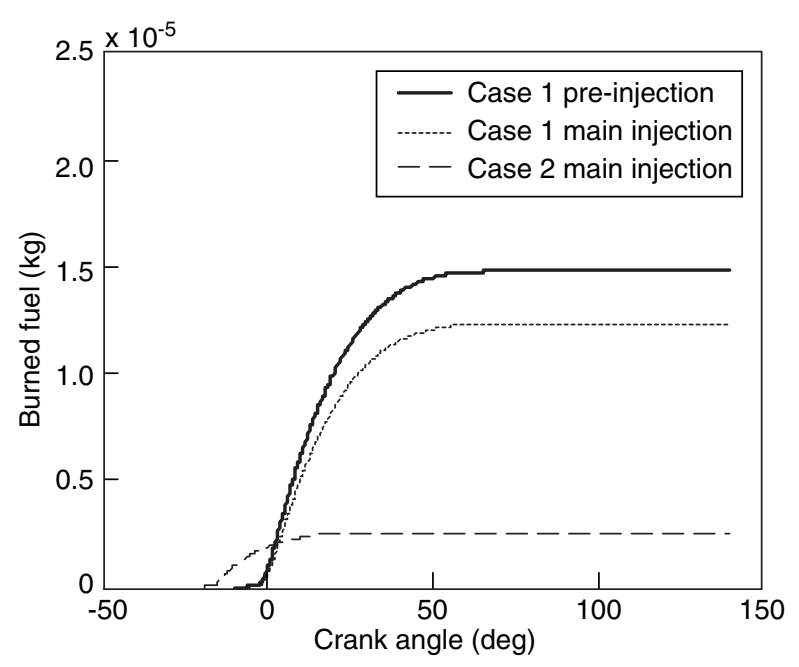

Figure 5

Simulated Burned Fuel for test cases 1 and 2.

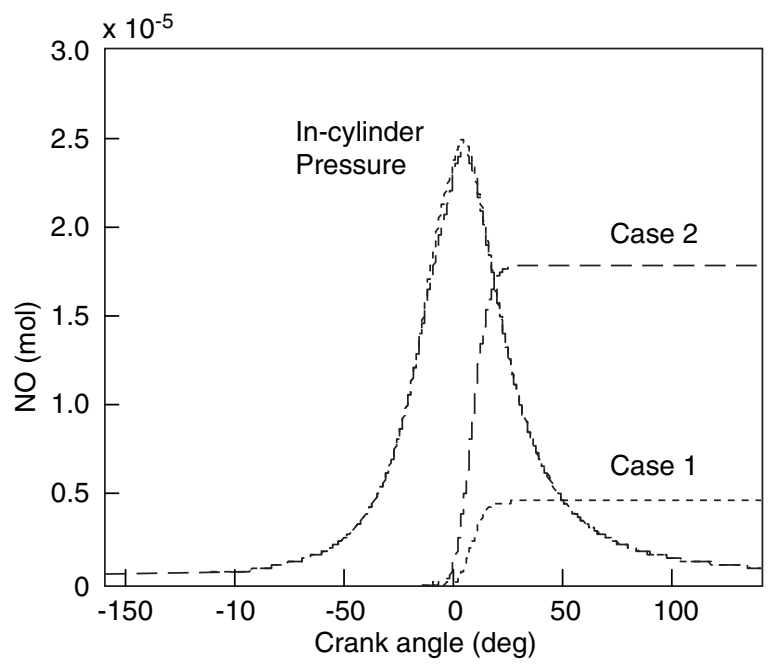

Figure 7

Simulated NO formation for test cases 1 and 2. 
Figure 8 through Figure 11 show the comparison between predicted and measured in-cylinder pressure traces for four engine operating conditions, with different engine speed and load and in case of single or multiple injections; in all cases the model exhibits a very good accuracy in predicting the engine cycle, even in the most critical conditions at low load and in case of multi-injection (i.e. Fig. 8). It is worth noting that all the figures refer to operating conditions not included in the identification set. Therefore the results confirm the good features of the regression models used to predict the parameters $C_{D}$ and $t_{i n j, d}$.

The model accuracy on the whole data set is shown in Figure 12 which shows the distribution of the mean squares relative error of the in-cylinder pressure (MSE), computed as:

$$
M S E=\sqrt{\frac{1}{\theta_{E V O}-\theta_{E V C}} \cdot \sum_{i=\theta_{I V C}}^{\theta_{E V O}}\left(\frac{p_{\text {sim }, i}-p_{\text {meas }, i}}{p_{\text {meas }, i}}\right)^{2}}
$$

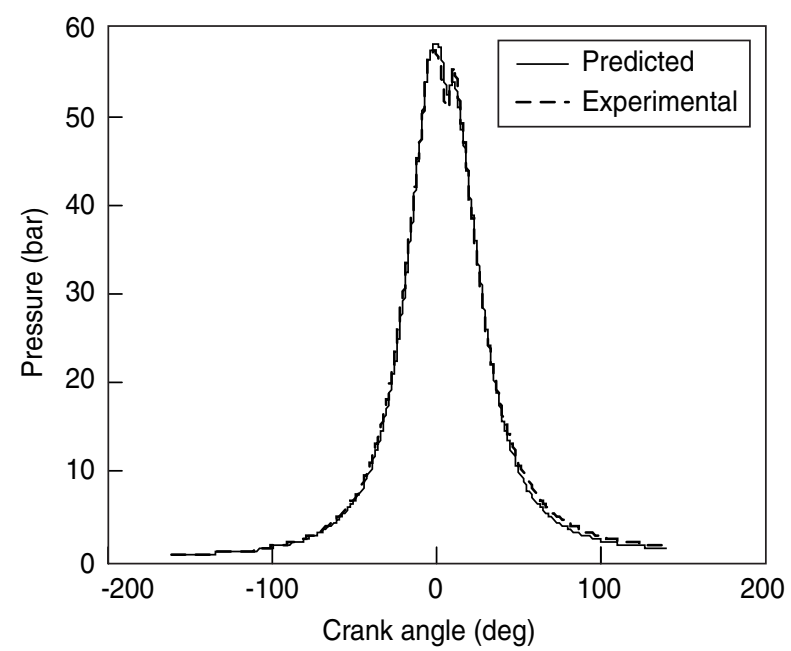

Figure 8

Comparison between predicted and measured pressure cycle. Engine speed $=2000 \mathrm{rpm}, \mathrm{BMEP}=2.0 \mathrm{bar}$ - pre and main injections.

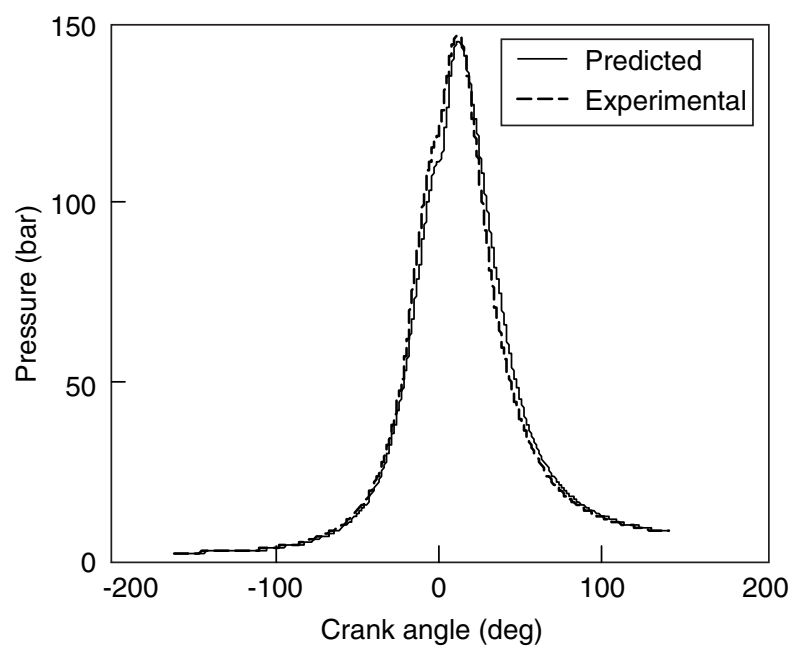

Figure 10

Comparison between predicted and measured pressure cycle. Engine speed $=2000 \mathrm{rpm}, \mathrm{BMEP}=17.0 \mathrm{bar}-$ pilot, pre and main injections.

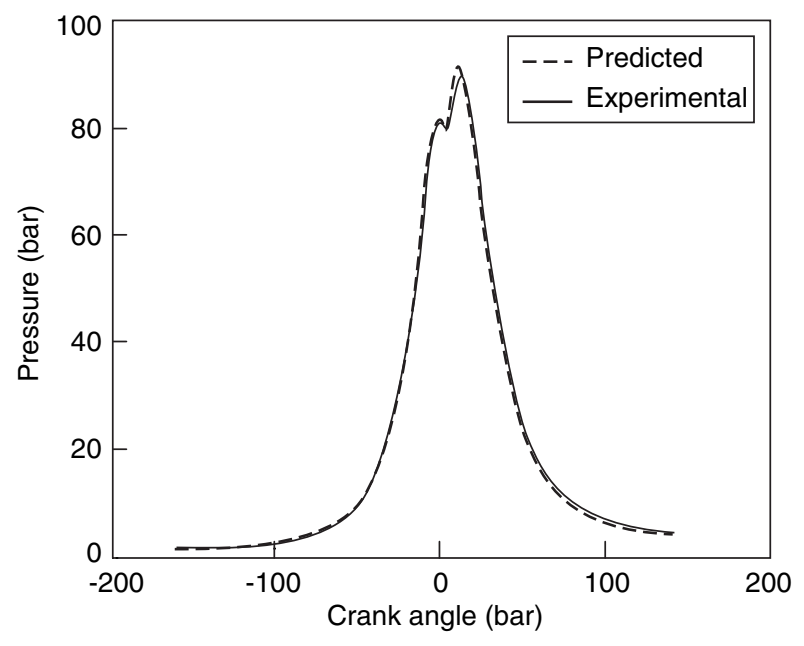

Figure 9

Comparison between predicted and measured pressure cycle. Engine speed $=2000 \mathrm{rpm}, \mathrm{BMEP}=9.0 \mathrm{bar}-$ pre and main injections.

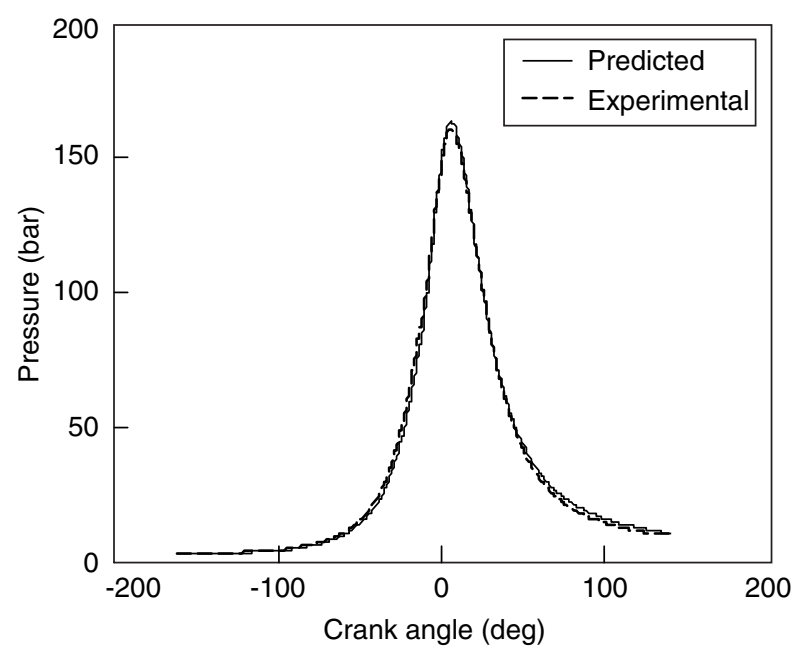

Figure 11

Comparison between predicted and measured pressure cycle. Engine speed $=4000 \mathrm{rpm}, \mathrm{BMEP}=15.0$ bar - only main injection. 


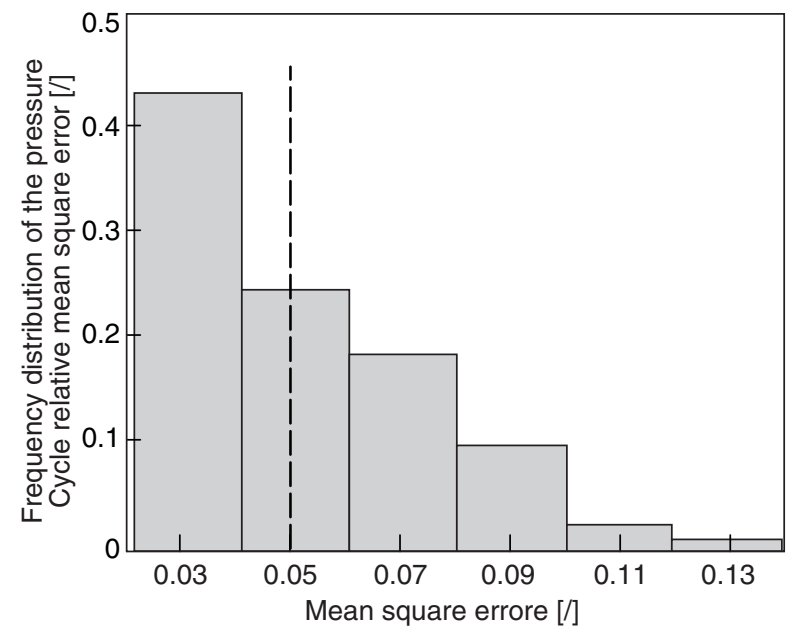

Figure 12

Frequency distribution of the Pressure Cycle Mean Square Error (MSE).

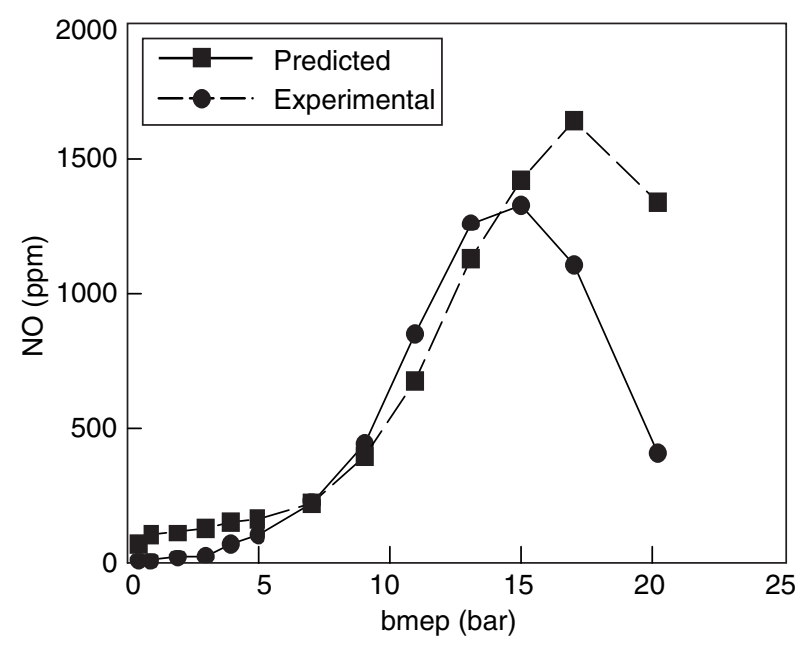

Figure 14

Comparison between predicted and measured NO emissions vs. bmep at $2500 \mathrm{rpm}$.

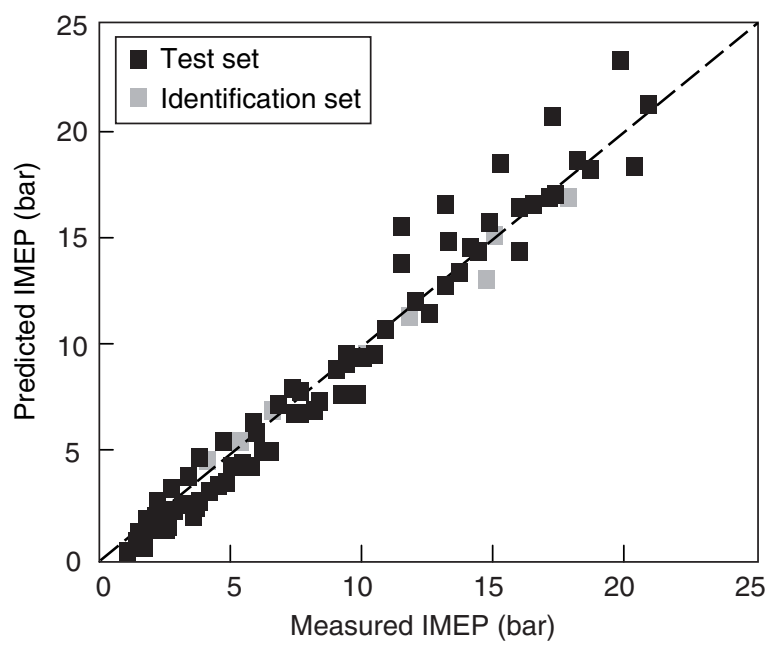

Figure 13

Comparison between predicted and measured IMEP for the whole dataset. $\mathrm{R}=0.98$.

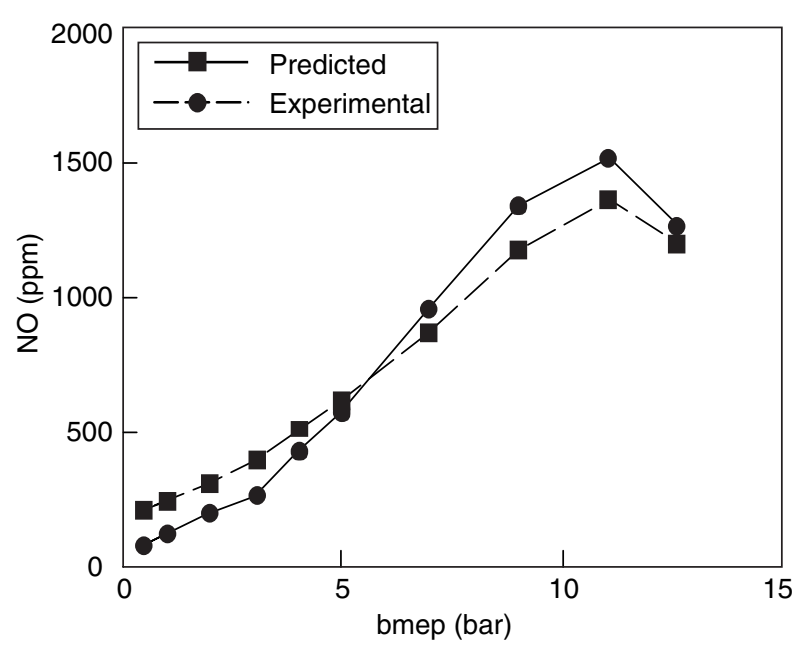

Figure 15

Comparison between predicted and measured NO emissions vs. bmep at $4500 \mathrm{rpm}$.
The MSE exhibits the expected distribution with a mean value of approximately $5 \%$. In order to better evidence the accuracy achieved over the whole engine operating range, in Figure 13 the comparison between measured and predicted gross IMEP is shown. The whole dataset is composed of 81 operating conditions from the test set and 9 operating conditions from the identification set. The figure evidences a satisfactory agreement between measured and predicted IMEP, apart from seven points which are out of the trend. These points correspond to the engine operation at high load and low engine speed with multiple injections, which differs significantly from the engine operating range spanned in the identification set (Table 1). Nevertheless, it is worth to note that the overall accuracy is more than satisfactory for the model purposes, with a correlation index $R$ equal to 0.98 .

Concerning emissions prediction, Figure 14 through Figure 17 show the comparison between measured and estimated NO and soot emissions vs. BMEP at 2500 and 


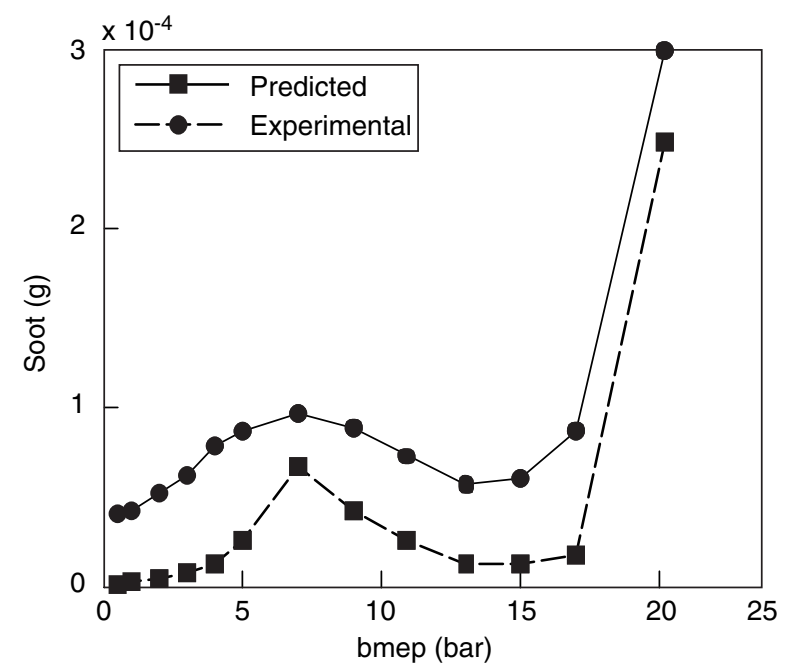

Figure 16

Comparison between predicted and measured soot emissions $v s$. bmep at $2500 \mathrm{rpm}$.

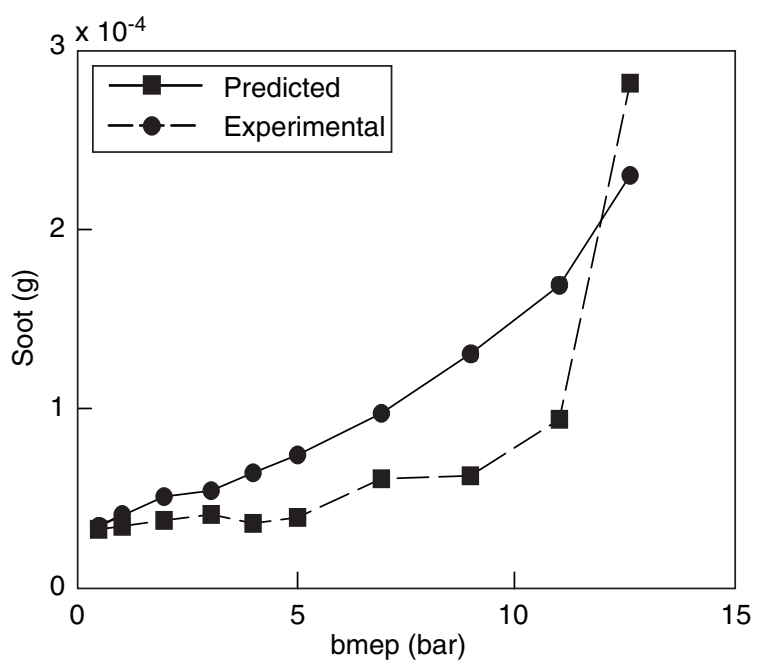

Figure 17

Comparison between predicted and measured soot emissions vs. bmep at $4500 \mathrm{rpm}$.
4500 rpm. Particularly, Figure 14 and Figure 15 exhibit a satisfactory accuracy of the model in predicting NO emissions vs. engine load (BMEP), especially at high engine speed (i.e. $4500 \mathrm{rpm}$ ). At low speed (i.e. $2500 \mathrm{rpm}$ ) the model lacks accuracy at high load, though the trend is well predicted in the whole BMEP range.

Model features in estimating soot emissions are shown in Figures 16,17 . The results evidences a satisfactory accuracy in predicting the trend of soot formation with engine load, especially at low engine speed (i.e. $2500 \mathrm{rpm}$ ) where a sinusoidal behaviour is detected. At high engine speed, the soot formation is overestimated at medium load while the peak value is underestimated.

The exhaust emissions results evidence that model estimations are accurate enough for most of the engine operating conditions, except for some particular regions. Nevertheless, in the whole engine operating range the model is useful to predict the trend of $\mathrm{NO}$ and soot emissions as function of engine load, speed and especially control variables. These features clearly emerge in Figure 18 and Figure 19 which show the effects of injection timing and rail pressure on engine performance and emissions. Figure 18 shows that the IMEP experiences a quadratic trend with the injection timing, with a peak value increasing with the rail pressure. This behaviour is due to the occurrence of an enhanced air/fuel mixture that results in a reduced combustion time delay, with benefits at medium-low advance (i.e. $10 \div 5$ deg [ATDC]). On the other hand when the injection timing is advanced more than $15 \mathrm{deg}$, the reduced time delay results in an anticipatory combustion with lower IMEP.
The effects of injection timing and rail pressure on $\mathrm{NO}$ emissions are shown in Figure 19 indicating an increase in pollutants with both control variables. This behaviour is explained considering that increasing injection advance and rail pressure results in higher temperatures and more homogeneous mixtures in the mixing zone, with effects on kinetic constants and oxygen concentration of Zeldovich

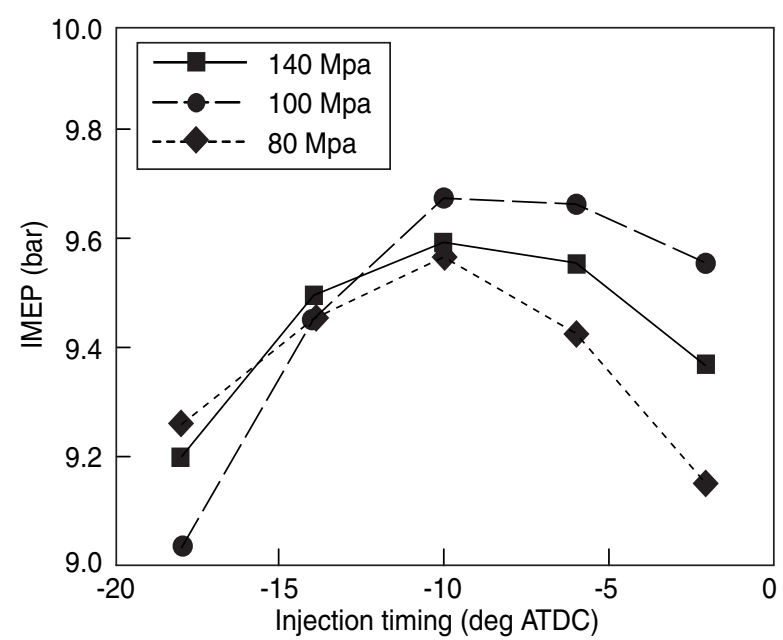

Figure 18

Effects of injection timing and rail pressure on IMEP. 
mechanism. An opposite trend is detected for soot formation which is enhanced by the occurrence of heterogeneous fuel/air mixtures and fuel droplets; as evidenced in the figure, soot emissions reduce as the rail pressure is increased and the minimum values are reached in case of advanced injection that improve the soot oxidation.

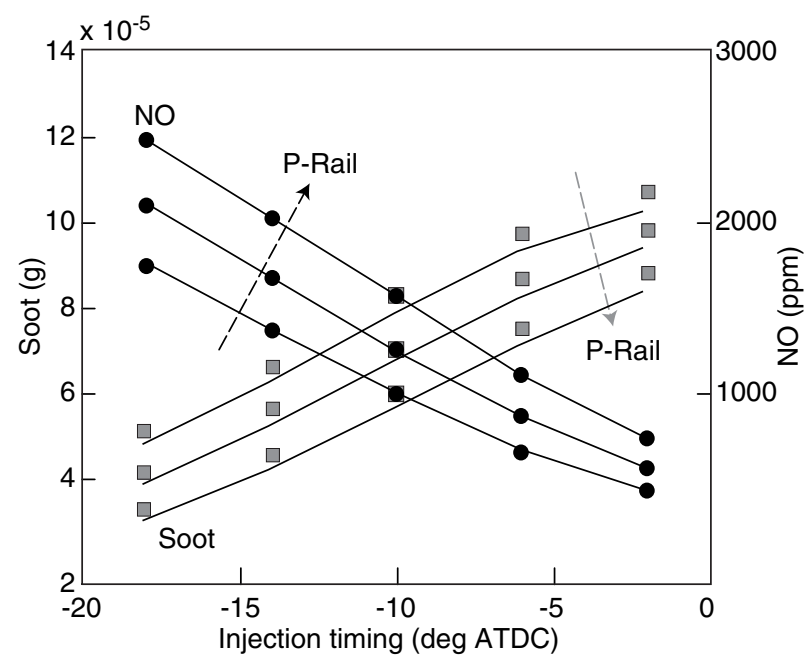

Figure 19

Effects of injection timing and rail pressure on $\mathrm{NO}$ and soot emissions.

\section{CONCLUSION}

A two-zone model has been presented for the simulation of jet formation, combustion and emissions in a Common-Rail Multi-Jet Diesel Engine.

An accurate identification analysis has been accomplished on the two parameters of the model which have been correlated to engine operation by multiple regressions. This result ensures model predictability in a wide engine operating range with a limited recourse to experiments: 9 engine cycles have been used for model identification.

Model accuracy has been tested via comparison between measured and simulated pressure cycle, $\mathrm{NO}$ and soot emissions, on a dataset composed of 81 operating conditions, in a wide range of engine speed and load, and in case of single and multiple injections. The overall accuracy is more than satisfactory with a mean square error on the pressure cycle equal to 5\% and a correlation index between measured and predicted imep of 0.98 .
The simulation results indicated that the model predicts the effects of different injection parameters (timing, dwell, duration, rail pressure) on performance and emissions in case of single and multiple injections in accordance with experimental investigations. Moreover the computational time (3 seconds per engine cycle on Pentium 4) is suitable for the use in the framework of engine control system design, for intensive simulation and optimization processes.

\section{REFERENCES}

Arsie I., Pianese C., Rizzo G. (1998) Models for the Prediction of Performance and Emissions in a Spark Ignition Engine - A Sequentially Structured Approach, SAE Paper 980779.

Arsie I., Di Genova F., Pianese C., Sorrentino M., Rizzo G., Caraceni A., Cioffi P., Flauti G. (2004) Development and Identification of Phenomenological Models for Combustion and Emissions of Common-Rail Multi-Jet Diesel Engines, SAE Paper 2004-01-1877.

Arsie I., Di Genova F., Pianese C., Rizzo G., Caraceni A., Cioffi P., Flauti G. (2005) Thermodynamic Modeling of Jet Formation and Combustion in Common Rail Multi-Jet Diesel Engines, SAE Paper 2005-01-1121.

Arsie I., Di Genova F., Mogavero A., Pianese C., Rizzo G., Caraceni A., Cioffi P., Flauti G. (2006) Multi-Zone Predictive Modeling of Common-Rail Multi-Injection Diesel Engines, SAE Paper 2006-01-1384.

Assanis D.N., Heywood J.B. (1986) Development and Use of a Computer Simulation of the Turbocompounded Diesel System for Engine Performance and Component Heat Transfer Studies, SAE Paper 860329.

Barba C., Burkhardt C., Boulouchos K., Bargende M. (2000) A Phenomenological Combustion Model for Heat Release Rate Prediction in High-Speed DI Diesel Engines Whit Common Rail Injection, SAE Paper 2000-01-2933.

Bella G., Rocco V., Ubertini S. (2002) Combustion and Spray Simulation of a DI Diesel Engine Models, SAE Paper 2002-012776.

Bi X., Yang M., Han S., Ma Z. (1999) A Multi-Zone Model for Diesel Spray Combustion, SAE Paper 1999-01-0916.

Corcione F.E., Fusco A., Valentino G., Papetti F. (1993) Numerical and Experimental Analysis of Diesel Air Fuel Mixing, SAE Paper 931948.

Ferguson C.R. (1986) Internal Combustion Engine, Applied Thermosciences, John Wiley.

Heywood J.B. (1988) Internal Combustion Engine Fundamentals, MC Graw Hill.

Hiroyasu H., Masataka Arai (1990) Structures of Spray in Diesel Engines, SAE Paper 900475.

Hiroyasu H., Kadota T. (1983) Development and Use of a Spray Combustion Modeling to Predict Diesel Engine Efficiency and Pollutant Emission, Bull. ASME 26, 214.

Jung D., Assanis D.N. (2001) Multi-Zone Model DI Spray Combustion Model for Cycle Multi-Zone DI Diesel Spray Combustion Model for Cycle Simulation Studies of Engine performance and Emissions, SAE Paper 2001-01-1246.

Kouremenos D.A., Rakopoulos C.D., Hountalas D.T. (1997) MultiZone Combustion Modeling for the Prediction of Pollutant Emissions and Performance of DI Diesel Engine, SAE Paper 970635 . 
Patterson M.A., Kong S.C., Hampson G.J., Reitz R.D. (1994) Modeling the Effects of Fuel Injection Characteristics on Diesel Engine Soot and NOx Emissions, SAE Paper 940523.

Rakopoulos C.D., Rakopoulos D.C., Kyritsis D.C. (2003) Development and Validation of a Comprehensive two-zone Model for Combustion and Emissions Formation in a DI Diesel Engine, Int. J. Energ. Res. 27, 1221-1249.
Ramos J.I. (1989) Internal Combustion Engine Modeling, Hemisphere Publishing Corporation, NY.

Shrivastava R., Hessel R., Reitz R.D. (2002) CFD Optimization of DI Diesel Engine Performance and Emissions Using Variable Intake Valve Actuation with Boost Pressure, EGR and Multiple Injections, SAE Paper 2002-01-0959.

Final manuscript received in October 2006. or distributed for profit or commercial advantage and that copies bear this notice and the full citation on the first page. Copyrights for components of this work owned by others than IFP must be honored. Abstracting with credit is permitted. To copy otherwise, to republish, to post on servers, or to redistribute to lists, requires prior specific permission and/or a fee: Request permission from Documentation, Institut français du pétrole, fax. +33147527078 , or revueogst@ifp.fr. 